\title{
Skin Rashes After Using Hydroxychloroquine in a COVID-19 Patient
}

\author{
(1) Petek Üstün, (1) Esra Adıșen, (1) Ayșegül Satılmıș
}

Gazi University Faculty of Medicine, Department of Dermatology, Ankara, Turkey

\section{ABSTRACT}

Hydroxychloroquine is an antimalarial drug which is also used in various chronic diseases such as systemic lupus erythematosus and rheumatoid arthritis because of its anti-inflammatory and antiviral effects. Recently, it's frequently preferred as a treatment alternative in the Coronavirus disease-2019 (COVID-19) pandemic. Skin side effects of hydroxychloroquine range from side effects such as pruritus, urticaria, alopecia, dry skin, pigment changes, redness to serious Stevens-Johnson-like life-threatening rashes. Herein, we report a patient who was infected with COVID-19 and started hydroxychloroquine and had a rash on her hands after a short time. Contact dermatitis is one of the first diagnoses to be considered in the differential diagnosis, since lesions are only seen on the hand. Our patient did not respond despite the use of topical corticosteroids, which are used as the first step in the treatment of contact dermatitis. Another disease that should be considered in the differential diagnosis of our patient is phototoxic and photoallergic contact dermatitis, which is well-known to be caused by hydroxychloroquine. Although it is clinically difficult to distinguish contact dermatitis from photo-induced dermatitis, the fact that our patient was exposed to intense sunlight during drug use is a clue to the diagnosis of photo-induced skin reaction.

Keywords: Hydroxychloroquine, Dermatitis, Photo-induced, Drug eruption, COVID-19

\section{Introduction}

Hydroxychloroquine is a drug developed to prevent and treat malaria; it is also used in various chronic diseases such as systemic lupus erythematosus and rheumatoid arthritis due to its antiinflammatory and antiviral effects. Since hydroxychloroquine has previously been shown to be effective in HIV and SARS infections, it has been considered as a treatment alternative for researchers in the Coronavirus disease-2019 (COVID-19) pandemic [1].

Although hydroxychloroquine most commonly causes gastrointestinal and dermatological side effects, these side effects are mostly mild and usually do not require discontinuation of the drug. Neuropathy, retinopathy, cardiotoxicity and myopathy in the proximal muscles are known serious adverse events and are rarely seen [1]. Skin side effects of antimalarial drugs range from side effects such as pruritus, urticaria, alopecia, dry skin, pigment changes, redness to serious Stevens-Johnson-like life-threatening rashes [2]. We wanted to present you with a patient who was infected with COVID-19 and started hydroxychloroquine and had a rash on her hands after a short time.

\section{Case Report}

A 30-year-old woman who works as a secretary in the Dermatology Department of Gazi University Hospital applied to the outpatient clinic for routine COVID-19 screening on $30^{\text {th }}$ April. She had no symptoms such as cough, sore throat, headache, fatigue, which could be related to SARS-CoV-2. Coronavirus conventional polymerase chain reaction test taken from the throat swab was positive. She started to receive hydroxychloroquine at a dose of 400 mg and ascorbic acid 1000 mg daily. The patient had continued the treatment for 10 days, and 3 days after the treatment was 
stopped, the patient complained of redness, dryness, and peeling on her hands. The rashes were more pronounced, especially on the fingertips and interphalangeal joints, and the exfoliation and dryness gradually spread to the palms. There was tenderness on palpation in the rashes and the patient complained of itching (Figures 1, 2).

She reported that she had no personal or family history of drug eruptions and had never experienced such a rash before. On dermatological examination, erythematous desquamative plaques were present on fingertips and over interphalangeal joints and

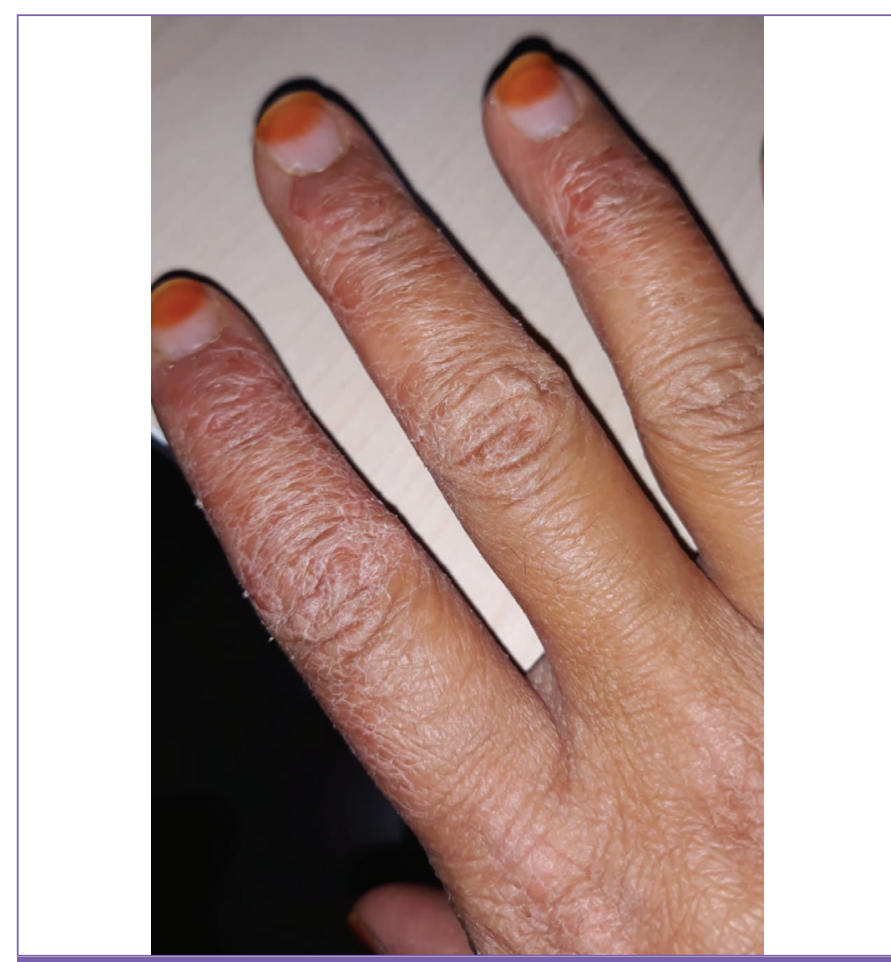

Figure 1. Erythematous desquamative plaques on interphalangeal joints, lichenification and exaggerated skin lines

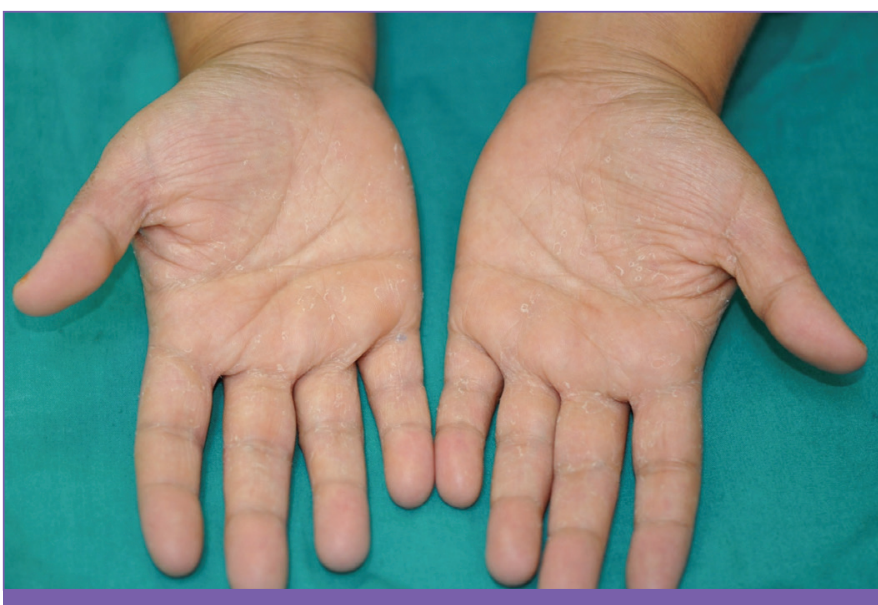

Figure 2. Desquamation on palmar surface of hands there was desquamation on the bilateral palmar surfaces. When the patient's history was detailed, it was learned that the patient spent time in her garden and was exposed to intense sunlight. Betamethasone valerate + fusidic acid combination was initiated to the patient, and the patient's medication was changed to methylprednisolone aceponate, as the lesions did not regress in the control examination on the $3^{\text {rd }}$ day. In the control examination of the patient one week later, there was still no improvement in the lesions.

\section{Discussion}

In the COVID-19 pandemic, the frequency of eczematous rashes on the hand has increased and the most common reason is the frequent use of disinfectants. In the present case, contact dermatitis is one of the first diagnoses to be considered in the differential diagnosis, since lesions are only seen on the hand. While irritant contact dermatitis is the most common contact dermatitis, it is followed by atopic dermatitis, allergic contact dermatitis, and eczematous dermatitis [3].

Although itching, tenderness, and hyperkeratosis observed in our case are also seen in irritant contact dermatitis, our patient did not respond despite the use of topical corticosteroids, which are used as the first step in the treatment of contact dermatitis. Another disease that should be considered in the differential diagnosis of our patient is phototoxic and photoallergic contact dermatitis, which is well-known to be caused by hydroxychloroquine. In the literature, a patient with long-term hydroxychloroquine use had itchy, eczematous dermatitis on the face and hands triggered in the summer, and the photo-test result with narrow-band ultraviolet B was positive [4]. Although it is clinically difficult to distinguish contact dermatitis from photo-induced dermatitis, the fact that our patient was exposed to intense sunlight during drug use is a clue to the diagnosis of photo-induced skin reaction.

As a result, light exposure should be questioned in skin rashes that occur during the use of photo-sensitizer drugs such as hydroxychloroquine, and photo-induced skin reactions should be considered in the differential diagnosis.

\section{Ethics}

Informed Consent: Consent form was filled out by all participants.

Peer-review: Externally and internally peer-reviewed.

\section{Authorship Contributions}

Surgical and Medical Practices: E.A., Concept: E.A., Design: A.S., Data Collection or Processing: E.A., P.Ü., Analysis or Interpretation: P.Ü., A.S., Literature Search: P.Ü., A.S., Writing: P.Ü.

Conflict of Interest: No conflict of interest was declared by the authors. 
Financial Disclosure: The authors declared that this study received no financial support.

\section{References}

1. Sinha N, Balayla G. Hydroxychloroquine and COVID-19. Postgrad Med J 2020;96:550-555.

2. Salido M, Joven B, D'Cruz DP, Khamashta MA, Hughes GR. Increased cutaneous reactions to hydroxychloroquine (Plaquenil) possibly associated with formulation change: comment on the letter by Alarcón. Arthritis Rheum 2002;46:3392-3396.

3. Blicharz L, Czuwara J, Samochocki Z, Goldust M, Chrostowska S, Olszewska M, Rudnicka L. Hand eczema-A growing dermatological concern during the COVID-19 pandemic and possible treatments. Dermatol Ther 2020;33:e13545.

4. Lisi P, Assalve D, Hansel K. Phototoxic and photoallergic dermatitis caused by hydroxychloroquine. Contact Dermatitis 2004;50:255-256. 